\title{
Natural Disasters in Nigeria: An Econometric Model
}

\author{
Emmanuel Okokondem Okon $^{1}$
}

\begin{abstract}
${ }^{1}$ Department of Economics, Kogi State University, Anyigba, Kogi State, Nigeria
Correspondence: Department of Economics, Kogi State University, Anyigba, Kogi State, Nigeria, E-mail: tonydom57@yahoo.com. Tel: +2348023275716
\end{abstract}

Received: January 12, 2018

Accepted: January 17, 2018

Online Published: February 8, 2018

\section{Abstract}

This paper models and estimates the occurrence of natural disaster in Nigeria using the residual-based test for cointegration within an autoregressive distributed lag (ARDL) framework and error correction specification between the period 1970 and 2016, the results from the estimated static model shows that DLOG(TEM), LOG(GDPC) and LOG(URB) are long-run determinants of natural disasters in Nigeria. The short run error correction model results revealed that the coefficients of DLOG(CO2), DLOG(WIS), LOG(GDPC), LOG(URB), DLOG(GDPC(-2)) and LOG(URB(-1))seem to be significant and helpful in explaining the occurrence of natural disaster (NAD)in Nigeria. The error correction term shows that speed of adjustment of disequilibrium in natural disaster (NAD) in the previous year which is corrected in the current year is about 44.3 percent. Therefore, Nigerian government should among other recommendations embark on reducing urbanization growth by making sure that industries which forge linkages with rural occupations should be promoted to mitigate a high rural-urban migration. Establishing of very effective early warning systems for meteorological, geophysical, biological, social and industrial hazards should be ensured.

Key words: Natural Disaster, Autoregressive Distributed Lag Model.

\section{Introduction}

Economic growth, reflected in increases in national output per capita, makes possible an improved material standard of living. Sustainable development, popularly and concisely defined as 'meeting the needs of the present generations without compromising the ability of future generations to meet their needs,' directly addresses the utilization of natural resources, the state of the environment, and intergenerational equity (Hess, 2013). UN organizations, various international institutions, and governments have placed importance on natural disasters and sustainable development (ADRC, 2003).

During the past four decades, natural hazards such as earthquakes, volcanic activity, landslides, tsunamis, tropical cyclones and other severe storms, tornadoes and high winds, river floods and coastal flooding, wildfires and associated haze, drought, sand/dust storms, and insect infestations have caused major loss of human lives and livelihoods, the destruction of economic and social infrastructure, as well as environmental damage(ISDR, 2003). Economic losses have increased almost ten times during this period. In recent years, floods in Algeria, Bangladesh, Ethiopia, Guinea, India, Mozambique, Nigeria, Sudan, Thailand, Venezuela and Vietnam, volcanic eruptions in Ecuador, Democratic Republic of Congo, Indonesia, Montserrat, and the Philippines, and earthquakes in Afghanistan, El Salvador, India, Indonesia, Japan, Peru and Turkey, have created widespread social, economic and environmental destruction. In some cases, natural disasters can amplify man-made emergencies or vice versa, as epitomized by the drought, earthquakes and unfolding events in Afghanistan (ISDR, 2003).

The escalation of severe disaster event striggered by natural hazards and related technological and environmental disasters is increasingly threatening both sustainable development and poverty-reduction initiatives. The loss of human lives and the rise in the cost of reconstruction efforts and loss of development assets has forced the issue of disaster reduction and risk management higher on the policy agenda of affected governments as well as multilateral and bilateral agencies and NGOs (ISDR, 2003). This trend led to the adoption of the International Strategy for Disaster Reduction (ISDR) by governments to succeed and promote implementation of the recommendations 
emanating from the International Decade for Natural Disaster Reduction (1990-1999). The aim of the ISDR is to mobilize governments, UN agencies, regional bodies, the private sector and civil society to unite efforts in building resilient societies by developing a culture of prevention and preparedness(ISDR, 2003).

In the light of this, the National Emergency Management Agency (NEMA) was established via Act 12 as amended by Act 50 of 1999, to manage natural and man-disasters in Nigeria. Basically it formulates policy on all activities relating to disaster management and coordinates the plans and programmes for efficient and effective response to disasters at national level (Shuaib, 2009). Indeed, the fallout of the recent flooding in the year 2012 shows how far Nigeria is from meeting the demands of managing natural disasters (Tribune, 2012). Hundreds of villages were destroyed and thousands of people were affected by the floods, which occurred after heavy rainfall caused the Benue River to rise above its banks. The situation was further complicated by additional water that was released from a dam in neighboring Cameroon. In some places, houses were totally submerged, their residents forced to flee (MSF, 2012). Out of Nigeria's 36 states, 32 were affected by the floods (OCHA, 15 Nov 2012).

Nigeria is so blessed that the cases of natural disasters are few and far between; and even the few cases of natural disasters that the country has experience are mild compared to what some developed countries of the world have had to contend with (Orhewere, 2012). The aim of this paper is to build an empirical model that will help to understand the mechanism of natural hazards of atmospherical, geological, hydrological, and biological origins and to analyze the transformation of these hazards into disasters. This paper is of importance because of the emphasis on disaster response and humanitarian assistance which have absorbed significant amounts of resources that could have been allocated for development efforts. If this trend were to persist, coping capacities of Nigeria will likely be overwhelmed. As such the paper offers proactive measures to prevent occurrence of natural disaster instead of reactionary measures to such crises. The intention is to increase the resistance of the society to natural disasters. The rest of the paper is therefore organized as follows. Following the introductory section, Section 2 reviews the literature. After examining natural disaster and sustainable Development in Nigeria, Section 3 also specification an estimation model. An econometric analysis of natural disaster in Nigeria is presented in Section 4 while Section 5 presents the summary, conclusions and policy implications.

\section{Review of Related Literature}

Sustainable development means encouraging economic growth while protecting the environment and improving our quality of life (Gov.UK, 2013). For as long as historical records of extreme events in the natural environment have been kept, statistics indicate an increasing frequency of disasters (Zenklusen, 2007). In the second half of the $20^{\text {th }}$ century the number of large natural catastrophes doubled and yearly damages in monetary terms increased by more than a factor of 6 (Munich Re, 2006). Causes and effects of disasters appear to be closely related to economic development. In rich countries, natural catastrophes involve physical damage and few casualties, whereas in the developing world the human cost is far greater. Globally, more than $90 \%$ of total lives lost to natural disasters are due to events in developing countries (Kreimer and Arnold, 2000; GuhaSapir et al., 2004). In absolute monetary terms, natural disasters entail greater damages in industrialized countries while in relation to GDP, impacts appear primarily significant in the developing world (Mechler, 2003). A variety of explanations is put forward in the literature for both the increase in disaster impacts over time and their contrasting repercussions in developing and industrialized countries. Firstly, global demographic dynamics and economic growth expose more people and their assets to risk. Secondly, urbanization leads to a concentration of population, wealth and increasingly complex economic activities. A trend which may be accompanied by the growth of cities onto marginal lands. In combination, these processes can increase both the vulnerability of socio-economic systems and their exposure to natural hazards (Zenklusen, 2007). Thirdly, anthropogenic changes to the natural environment from local deforestation to global climate change are assumed in most of the literature to contribute to the rising frequency of extreme weather events and to their increasingly disastrous effects. Finally, development appears to explain differences in the vulnerability of physical structures and socio-economic systems to extreme events in the natural environment. In other words: disaster risk is a ramification of poverty - at the level of individuals, households, regions and countries (Zenklusen, 2007).

If the distribution of catastrophic risk is influenced by the level of development, what are, in reversed causality, the effects of natural disasters on development (Zenklusen, 2007)? On this problem, there is considerable disagreement in catastrophe literature. Contrasting statements on the macroeconomic repercussions of disasters and their effects on growth and development indicate an intense debate. DHA (1994), for example, concludes that "disasters frequently wipe out years of development programming and set the slow course of improvement in the third world countries further behind, wasting precious resources." ECLAC (2003) finds natural catastrophes to "have a major impact on the living conditions, economic performance and environmental assets and services of affected countries or regions. Consequences may be long term and may even irreversibly affect economic and social structures and the environment." Such statements, however, are not undisputed as is illustrated by Albala-Bertrand (1993) objections, 
which have become a classic in this debate: "... disasters are primarily a problem of development, they are not necessarily a problem for development."

3. Natural Disaster and Sustainable Development in Nigeria

The top 10 natural disasters in Nigeria between 1980-2011 show that they are mainly made up of drought, flood and epidemic. While drought affected 3,000,000 people, flood inundated areas that led to the evacuation of 3,014,265 people and epidemic affected 80,000 people (see Table 1 in Appendix). In all, the ten top natural disasters affected $6,094,265$. Among the ten top natural disasters that affected Nigeria, flood has highest frequency and affected more people. All the major floods that led to the displacement of people in Nigeria occurred between 1980 and 2000 decades (Odjugo, 2012).This period coincided with the period when rainfall becomes more erratic with higher intensity due to intensifying impacts of climate change (Odjugo, 2005, 2012).

In 2009 and 2010, Nigeria ranked 12th and 11th amongst countries with the highest reported levels of displacement by sudden-onset disasters worldwide, according to IDMC's global data. Flooding and soil erosion in the states along the Niger River and its tributaries, River KatsinaAla and River Benue regularly cause internal displacement. About a million people living in the low-lying plains of the River Niger are considered at risk (Chinedu, 2008; U.S.DOS, 2011).

According to the National Emergency Management Agency, floods and storms displaced thousands of people in 2011 and up to two million people in 2010, mainly in Jigawa, Sokoto and Kebbi States (IDMC, 2012a). The 2010 floods where notably triggered by the opening of floodgates on the Challawa and Tiga dams by the authorities, following heavy rains (BBC, 24 Sept. 2010). Floods displaced another 140,000 people in 2009 (Dartmouth Floods Observatory) (IDMC, 2012b). Affected states included Zamfara, Kaduna, Niger, Benue, Adamawa, Nassarawa, Sokoto, Jigawa, and Abuja. Most recently, Nigeria witnessed a spate of floods that ravaged different parts of country in 2012, with the bursting of the banks of the Rivers Niger and Benue and their adjoining tributaries. From central Nigeria down to the south into the Niger Delta, unprecedented floods destroyed lives and properties worth billions in states within the drainage basin of the two rivers. Several hectares of farms, livestock, homes and infrastructures were destroyed. The Red Cross reports put the figure at 137 people killed (IDMC, 2012). Thousands of people were displaced from their homes due to the swelling floodwaters. The worst hit states were Kogi, Benue, Taraba, Anambra, Delta and the Niger Delta communities (IDMC, 2012).

The 10 deadliest natural disasters in Nigeria between 1980 and 2011 claimed 19,537 lives and they are epidemic in nature (see Table 1 in Appendix). The deadliest of the epidemic is the bacterial infectious disease (Cholera) which started 6th of May, 1991. It affected 10,000 people and killed 7,289 people in Bauchi and Kaduna States of Nigeria. The least among the 10 is also cholera that claimed 353 lives in July 2010. The 10 costliest disasters in Nigeria destroyed property worth $\$ 189.5 \mathrm{bn}$ (N30.3trillion) (seeTable1 in Appendix). Apart from the 1983 drought that destroyed property worth $\$ 71.7 \mathrm{bn}$, all other destructions resulted from flood. It is therefore obvious that among the 10 natural disasters in Nigeria, flood is the costliest and it affected more people while epidemic is the deadliest.

Nigeria is vulnerable to many hazards, including, but not limited to, fires, flooding, transportation and industrial accidents, and political conflicts (Ibem, 2011). Nigeria is vulnerable to these and other hazards and disaster impacts because of high population densities in urban areas (50\% of Nigerians live in urban areas) (Nwaka, 2005), an inability to integrate risk reduction measures into national development plans and programs (Abang, 2005), and poverty (NDMF 2010). In addition, scarcity of land, especially in urban centers like Lagos, has led to inordinate construction of structures in hazardous areas (NEMA, 2010; Ibem, 2011). Furthermore, the low level of disaster education is another reason why Nigeria is vulnerable to hazards (NEMA, 2010; Ibem, 2011).

Variables of sustainable development, primarily the Human Development Index and other economic factors, especially in a country like Nigeria which is affected by natural disasters shows that Nigeria's HDI value for 2012 is 0.471 - in the low human development category - positioning the country at 153 out of 187 countries and territories (UNDP, 2013). Between 2005 and 2012, Nigeria's HDI value increased from0.434 to 0.471, an increase of 9 percent or average annual increase of about 1.2 percent (UNDP, 2013). The rank of Nigeria's HDI for 2011 based on data available in 2012 and methods used in 2012 was- 154out of 187 countries (UNDP, 2013). In the 2011 HDR, Nigeria was ranked 156 out of 187 countries. However, it is misleading to compare values and rankings with those of previously published reports, because the underlying data and methods have changed (UNDP, 2013).

Table 2 reviews Nigeria's progress in each of the HDI indicators. Between 1980 and 2012, Nigeria's life expectancy at birth increased by 6.8 years, mean years of schooling increased by 0.2 years and expected years of schooling increased by 2.4 years. Nigeria's GNI per capita increased by about 34 percent between 1980 and 2012. 
Table 2: Nigeria's HDI trends based on consistent time series data, new component indicators and new methodology

\begin{tabular}{llllll}
\hline year & $\begin{array}{l}\text { Life } \\
\text { expectancy } \\
\text { at birth }\end{array}$ & $\begin{array}{l}\text { Expected } \\
\text { years } \\
\text { of } \\
\text { schooling }\end{array}$ & $\begin{array}{l}\text { Mean } \\
\text { years of } \\
\text { schooling }\end{array}$ & $\begin{array}{l}\text { GNI per } \\
\text { capita } \\
\mathbf{2 0 0 5} \\
\text { PPP\$) }\end{array}$ & HDI value \\
\hline 1980 & 45.5 & 6.6 & & 1,571 & \\
\hline 1985 & 45.9 & 8.4 & & 1,202 & \\
\hline 1990 & 45.6 & 6.5 & 1,274 & \\
\hline 1995 & 45.1 & 6.5 & & 1,303 & \\
\hline 2000 & 46.3 & 7.9 & & 1,285 & \\
\hline 2005 & 49 & 9 & 5 & 1,540 & 0.434 \\
\hline 2010 & 51.4 & 9 & 5.2 & 1,928 & 0.462 \\
\hline 2011 & 51.9 & 9 & 5.2 & 2,017 & 0.467 \\
\hline 2012 & 52.3 & 9.0 & 5.2 & 2,102 & 0.471 \\
\hline \multicolumn{5}{r}{ Source: UNDP (2013) } \\
\end{tabular}

Nigeria's economy is struggling to leverage the country's vast wealth in fossil fuels in order to displace the crushing poverty that affects about $57 \%$ of its population (Wikipedia, 2012). Economists refer to the coexistence of vast wealth in natural resources and extreme personal poverty in developing countries like Nigeria as the "resource curse". Although "resource curse" is more widely understood to mean an abundance of natural resources which fuels official corruption resulting in a violent competition for the resource by the citizens of the nation. Nigeria's exports of oil and natural gas - at a time of peak prices - have enabled the country to post merchandise trade and current account surpluses in recent years. Reportedly, $80 \%$ of Nigeria's energy revenues flow to the government, $16 \%$ covers operational costs, and the remaining $4 \%$ go to investors (Wikipedia, 2012). However, the World Bank has estimated that as a result of corruption $80 \%$ of energy revenues benefit only $1 \%$ of the population (Wikipedia, 2012). In 2005, Nigeria achieved a milestone agreement with the Paris Club of lending nations to eliminate all of its bilateral external debt. Under the agreement, the lenders will forgive most of the debt, and Nigeria will pay off the remainder with a portion of its energy revenues. Outside of the energy sector, Nigeria's economy is highly inefficient. Moreover, human capital is underdeveloped - as earlier stated, Nigeria ranked 153 out of 187 countries in the United Nations Development Index in 2012 (UNDP, 2013) — and non-energy-related infrastructure is inadequate.

4. Specification of Model

Natural disasters have their root causes in the normal activities of the earth. In recent generations however, man's increased knowledge and technology has served to trigger some natural disasters. A natural disaster is the consequence of a natural hazard which affects human activities. Human vulnerability, exacerbated by the lack of planning or appropriate emergency management, leads to financial, environmental or human losses. The resulting loss depends on the capacity of the population to support or resist the disaster, and their resilience (NA, n.d.). This understanding is concentrated in the formulation: "disasters occur when hazards meet vulnerability". A natural hazard will hence never result in a natural disaster in areas without vulnerability.

Since natural disasters are naturally occurring events, let's start by assuming that the occurrence of natural disaster depends on factors such as hydrometeorological, geophysical, biological and economic vulnerability:

$\mathrm{NAD}=f(\mathrm{HYD}, \mathrm{GPH}, \mathrm{BIO}, \mathrm{EVU})$

Where NAD is occurrence of natural disasters, HYD are hydrometeorological factors, i.e., natural processes or phenomena of atmospheric, hydrological or oceanographic nature that may cause loss of lives or injuries, property damage, social and economic disruption or environmental degradation. These include floods and wave surges, storms, landslides, avalanches, and droughts and related disasters (extreme temperatures and forest/scrub fires) (Odjugo, 2012).GPH are geophysical factors, i.e., natural earth processes or phenomena that may cause loss of lives or injuries, property damage, social and economic disruption or environmental degradation. These include earthquakes, tsunamis and volcanic eruptions. BIO are biological factors, i.e., processes of organic origin or those conveyed by biological vectors, including exposure to pathogenic microorganisms, toxins and bioactive substances, 
which may cause loss of lives or injuries, property damage, social and economic disruption or environmental degradation. These include epidemics and insect infestations (Odjugo, 2012).EVU is economic vulnerability.

The three groups of natural disaster are associated with distinct patterns and forms of economic vulnerability (EVU). This is in part because of differences in their frequency of occurrence and predictability. Vulnerability is the potential to suffer harm or loss, expressed in terms of sensitivity and resilience or of the magnitude of the consequences of the potential event. Lets further assume that the vulnerability of an economy to natural hazards is determined by a complex, dynamic set of influences relating to factors such as the type of natural hazard (TNH); the overall structure of an economy (OSE), including natural resource endowments; the geographic size of a country (GSC); the country's income level (GDP per capita)and stage of development (vulnerability is timedependent, the country's stage of socioeconomic development matters, as does its state of technical and scientific advancement); prevailing socioeconomic conditions (PSC), including the policy environment and the state of the economy (ISDR, 2003, ODI, 2005). It is presented as follows:

$\mathrm{EVU}=f(\mathrm{TNH}, \mathrm{GSC}, \mathrm{OSE}, \mathrm{GDP}, \mathrm{PSC})$

In terms of the estimation techniques, the scale and underlying determinants of natural disasters in a country would be best understood using systems-of-equations approaches. This is because of the interdependence of various factors. However, systems-of-equations approaches are also subject to statistical limitations, such as unavailability of data, the inability to correct for autocorrelation, a significant barrier to accuracy for most time-series studies. As such single equation models would be appropriate. Admittedly, they lack the ability to yield certain parameters, such as cross price elasticities that are calculable with a systems-of-equations approach. Nevertheless, despite its limitations, the single equation approach will be utilized because it allows for easy inclusion of various independent variables and is more statistically accurate. The linear- log version of it allows the estimated coefficients to be interpreted as elasticities or other magnitudes.

Accordingly, a preliminary functional form for natural disaster in Nigeria involves the following variables:

$\mathrm{NAD}=f(\mathrm{RAF}, \mathrm{TEM}, \mathrm{WIS}, \mathrm{CO} 2, \mathrm{GDPC}, \mathrm{PGR}, \mathrm{URB}, \mathrm{POE})$

Where NAD is a dummy variable used to capture the occurrence of natural disasters. The dummy variable takes the value of one if disaster occurs in a year and zero otherwise; RAF is rainfall; TEMP is temperature; CO2 is emission of Carbon dioxide; WIS is wind speed; GDPC is gross domestic product per capita; URB is urbanization rate; PGR is population growth rate and POE is institutional/political environment (proxy by corruption index)

Having defined the variables to include in the model, full specification of natural disaster function of Nigeria is now presented in a form that is estimable:

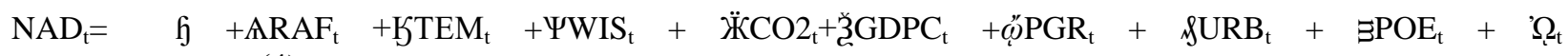
(4)

Where Gis constant term, $A, G, \Psi, \ddot{K}, \not{3}, \not ̈ \&$ and $ミ$ are coefficients that will be estimated empirically, $t$ represents time index denoting annual observations(1970 - 2016); and $Q$ is the error term.

Since the occurrence of natural disaster is a result of build-up of many factors (or continuous process), a dynamic specification of the natural disaster function with an autoregressive term that incorporates lagged values of the dependent and explanatory variables will be included in the set of regressors in order to capture the effect of previous factors. Equation 4 is now specified as a general dynamic equation called an autogressive distributed lag (ADL) of order $k$ as follows:

$k k k k k k k$

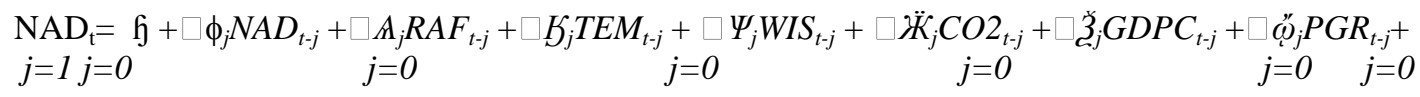

$k k$

$\square \mathscr{S U R B} B_{t-j}+\square ミ P O E_{t-j}+\breve{\mathrm{h}}_{t}$ $j=0 j=0$ 
All this does is to add lags 1 through $k$ of the dependent variable and all independent variables to the original model. It can be seen that the lags of the dependent variable start at $j=1$, and lags of the independent variables start at $j=0$ because of the need to include the contemporaneous values as in Equation 4. This equation can then be rewritten to obtain the error correction representation of the form:

$k k k k k k k$

$$
\begin{aligned}
& \Delta \mathrm{NAD}_{\mathrm{t}}=\mathrm{f}+\square \phi_{j} \square N A D_{t-j}+\square A_{j} \Delta R A F_{t-j}+\square \zeta_{j} \Delta T E M_{t-j}+\square \Psi_{j} \Delta W I S_{t-j}+\square \ddot{W}_{j} \Delta C O 2_{t-j}+\square \ddot{z}_{j} \Delta G D P C_{t-j}+\square \dddot{\omega}_{j} \Delta P G R_{t-j}+ \\
& j=1 \quad j=0 \quad j=0 \quad j=0 \quad j=0 \quad j=0 \\
& j=0 \\
& k k
\end{aligned}
$$

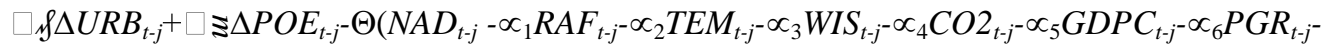

$$
\begin{aligned}
& j=0 \quad j=0 \\
& \left.\propto_{7} U R B_{t-j} \propto_{8} P O E_{t-j}\right)+\breve{И}_{t}
\end{aligned}
$$

The terms in parentheses in equation 6 represent the error correction term. The coefficients of this equation are functions of the coefficients of (5).

4.1 Data Source and Description of Variables

It must at the outset be recognized that estimation of natural disasters in the case of Nigeria (but also elsewhere) is beset with problems of data availability. The coverage for each of the variable spanned 1970 to 2016 (a period of 46 years). This is to ensure enough data points for the econometric analysis. Also, the frequency and intensity of natural disasters have increased considerably in recent years, which informed the choice of this period. The nature of the data is economical and meteorological. The use of annual data is preferable in the literature in order to avoid seasonality problems. With the exception of the dummy variable for natural disaster that was constructed using binary based on the chronology of natural disasters in Nigeria, other data were obtained from websites, journals, newspapers, various issues of Central Bank of Nigeria (CBN) -Annual Reports, Statistical Bulletin and Annual Abstracts of statistics of National Bureau of Statistics (NBS) formerly Federal Office of Statistics (FOS).

This paper does not try to quantify the economic and human loss of natural disasters, instead a dummy variable was used to capture the occurrence or infrequent of natural disasters that affect vulnerable communities or geographic areas of Nigeria, causing substantial damage, disruption, and perhaps casualties and leaving the affected communities unable to function normally. The natural disasters that are prevalent in Nigeria include, but are not limited to, flooding and droughts. The dummy variable (NAD) takes the value of one if disaster occurs in a year and zero otherwise. The dummy variable was used as a dependent variable. In the dynamic estimation, the lagged values of the dummy variable was included in order to capture the quality of the institution and preparedness based on past experience of natural disasters in the country, which will also serve as an indicator of vulnerable.

Other independent variables include rainfall, temperature, $\mathrm{CO} 2$ emission and vulnerability. The changes in temperature (TEM) and related local rainfall (RAF) variations affect the environment through accelerated desertification and land degradation. Floods are imminent if dams are full and need to be emptied quickly. In addition, the increased levels of carbon dioxide $(\mathrm{CO} 2)$ emissions are regarded by many scientists as the main reason for the ongoing climate change problem. According to scientists climate change could reach catastrophic proportions in form of frequent flooding, drought, global sea level rise, etc(EP, 2011). Wind is air that moves quickly as a result of natural forces. Air has certain mass $(\mathrm{kg})$ and mass density $(\mathrm{Kg} / \mathrm{m})$. Flow of air (wind) results in flow of mass (mass flow: $\mathrm{Kg} / \mathrm{s}$ ). The velocity attained by a mass of air traveling horizontally through the atmosphere is called wind speed (WIS). All these factors have a compound effect on the occurrence of natural disasters. On the one hand, they affect the intensity and frequency of extreme hydro meteorological events, and on the other hand, they increase the vulnerability of societies.

The country is subject to high rate of population growth (PGR). Poverty and social and economic pressures, such as, unemployment and illegal land tenure practices, make people more vulnerable by forcing them to live in dangerous locations, often on unsafe land, in unsafe shelters or low-cost dwellings and coastal areas, because there is no other land available at reasonable cost sufficiently close to employment opportunities.

Rapid urban growth (URB), particularly when it is accompanied by a large influx of people from rural areas, is one of the main factors contributing to increased vulnerability to natural disasters in many parts of Nigeria. The accelerated, and often uncontrolled, growth of cities has contributed to the ecological transformation of their immediate surroundings (pressure on scarce land, deforestation, etc.). In addition, the lack of appropriate drainage systems makes some cities susceptible to flash floods. 
Political and institutional vulnerability (POE)is understood as institutional weakness as a whole, and more specifically the weakness of the democratic system -with its negative effects on the efficiency of public policies, the legitimacy of government action, limited participation by citizens and the private sector in national efforts, linkage with local government actions and civil organizations, the handling and management of emergencies, processing of citizens' demands and needs, and the capacity to meet them (VRSD, n.d.). This has often been seen to be one of the prime causes of vulnerability to natural phenomena and in turn even a cause underlying other form of vulnerability. Economic development (GDPC) is widely understood as a process of increasing complexity that is reflected in the growing proportion of GDP accounted for by the secondary and tertiary sectors of the economy. The stage of development of an economy, measured in terms of the degree of sectoral, geographic, and financial integration, levels of economic specialization, and government revenue-raising capabilities, is likely to influence vulnerability to natural disasters (Benson and Clay, 1998). A developing country like Nigeria is typically perceived as most vulnerable, even though its absolute losses as a consequence of a particular disaster may be small relative to the levels reported in developed countries.

\subsection{The Modeling Process}

An important characteristic of the raw data being used for the regression is stationarity. When using time series modeling, various diagnostic tests and checks are employed as part of the estimation procedure. These tests are used to identify the most acceptable model and validate the data results (Walsh, 1997).

4.2.1. Stationarity Tests

4.2.1.1. The Augmented Dickey-Fuller (ADF) Test

To check the stationarity of the data described above, the Augmented Dickey-Fuller (ADF) test is applied. The Augmented Dickey-Fuller (ADF) test for autoregressive unit root tests the null hypothesis H0: $\mu=0$ against the one sided alternative $\mathrm{H} 1: \mu<0$ in the regression

$\Delta Y_{t}=\beta_{0}+\mu Y_{t-1}+\delta_{1} \Delta Y_{t-1}+\delta_{2} \Delta Y_{t-2}+\ldots+\delta_{p} \Delta Y_{t-p}+u_{t}$

Under the null hypothesis $\mu=0$, Yt has a unit root; under the alternate hypothesis, $\mathrm{Y}_{\mathrm{t}}$ is stationary. The ADF statistic is the OLS t-statistic testing $\mu=0$ in the equation above. If instead the alternate hypothesis is that $Y_{t}$ is stationary around a deterministic linear time trend, then this trend $\mathrm{t}$ (the period number), must be added as an additional regressor in which case the Dickey-Fuller regression becomes:

$\Delta Y_{t}=\beta_{0}+\alpha t+\mu Y_{t-1}+\delta_{1} \Delta Y_{t-1}+\delta_{2} \Delta Y_{t-2}+\ldots+\delta_{p} \Delta Y_{t-p}+u_{t}$

Where $\alpha$ is an unknown coefficient and the ADF statistic is the OLS statistic testing $\mu=0$ in the above equation.

The lag length $\mathrm{p}$ can be chosen using the Akaike's Information Criteria (AIC) because it known as the best information criteria to use. Burnham and Anderson (2004) argue that AIC has theoretical as well as practical advantage because it is derived from principles of information criteria. Yang (2005) also argues that the rate at which AIC converges to the optimum is the best possible. The general form for calculating AIC is:

$A I C=\frac{2 P}{T}-\frac{2 \ln L}{T}$

Where $L$ is likelihood value, $p$ is the number of parameters and $T$ is number of observation. Given a set of candidate values for the data, the preferred value is the one with the minimum AIC value.

The ADF test does not have a normal distribution under the null hypothesis, even in large samples (Girma, 2012).Critical values for the one sided ADF test depends on equations 7 and 8 used above. The null hypothesis of non-stationarity is tested using the t-statistic with critical values calculated by MacKinnon. The null hypothesis that $\mathrm{Y}_{\mathrm{t}}$ is non-stationary time series is rejected if $\mu$ are less than zero and statistically significant for each. The ADF test is unable to distinguish well between stationary and non stationary series with a high degree of autoregression. Given the inherent weakness of this test to distinguish between the null and the alternative hypotheses, DF-GLS test is also used. Essentially the test is an augmented Dickey-Fuller test except that the time series is transformed via a generalized least squares (GLS) regression before performing the test. It has significantly greater power than the previous versions of the augmented Dickey-Fuller test (Girma, 2012).

4.2.1.2 Residual-based Test for Cointegration

Therefore, the detection of cointegration is very important in practice prior to estimation. One of most popular tests for (a single) cointegration has been suggested by Engle and Granger (1987). For instance, let's consider the multiple regression: 


$$
y_{t}=\beta^{\prime} x_{t}+u_{t}, t=1, \ldots, \mathrm{T}
$$

where $x_{t}=\left(x_{I t} ; x_{2 t, \ldots,} x_{K t} ;\right)^{\prime}$ is the $k$-dimensional I(1) regressors. Notice that for $y_{t}$ and $x_{t}$ to be cointegrated, $u_{t}$ must be $I(0)$. Otherwise it is spurious. Thus, a basic idea behind is to test whether $u_{t}$ is $I(0)$ or $I(1)$.

The Engle and Granger cointegration test is carried out in two steps:

Firstly, the OLS regression of equation (10) is estimated and the residuals obtained by $\wedge$

$u_{t}=y_{t}-\beta^{\prime} x_{t,} t=1, \ldots, \mathrm{T}$

where $\beta$ are the OLS estimate of $\beta$.

In the case of this paper, the OLS regression of equation (4) is run.

Secondly, a unit root test is applied to $u_{t}$ by constructing an $\operatorname{AR}(1)$ regression for $u_{t}$ :

$\wedge \wedge$

$u_{t}=\phi u_{t-1}+\varepsilon_{t}$

That is, the Dickey-Fuller (ADF) test of $\mathrm{H} 0: \phi=1$ against $\mathrm{H} 1: \phi<1$ in (12) is conducted. This is called the residualbased EGDF cointegration test. Strictly, it is the test of no-cointegration, because the null of unit root in ${ }^{\wedge} \mathrm{u}_{\mathrm{t}}$ implies that there is no-cointegration between $y$ and $x$. So if $\mathrm{H}_{0}: \phi=1$ in (12) is rejected, the conclusion is that there is a cointegration and vice versa.

\subsection{Estimation Technique and Procedure}

Currently modern economic analysis involves the use of econometric methods where appropriate statistical and econometric test can be conducted to ensure the validity and reliability of the data and result, for accurate projection and prediction of the phenomenon in question (Articles, 2013). The multiple equation models is presented in equation

The empirical viability of the model will be tested using the ordinary least square (OLS) analytical technique. The use of OLS method according to koutsoyians (2001), yields parameter estimates with optimal properties such as unbiased minimum variance and efficient, thereby making the parameter estimates best linear and unbiased (BLUE). However, equation 4 is a static model and does not take into account the dynamics of natural disaster process. In order to capture the dynamics, the general specification of the ADLM is used. The exact lag length of the general ADLM is determined by the Akaike information criterion (AIC) and the Schwarz criterion (SC). The general-tospecific modelling approach is applied to reduce the number of explanatory variables in the initial equation, keeping only the underlying influencing factors based on both statistical significance and the sensible economic interpretation of the estimated parameters associated with these factors.

Within the general-to-specific framework, the specification starts from a general autoregressive distributed lag model (ADLM), which incorporates as many variables as possible supported by appropriate economic theory. The general ADLM is first estimated and the sum of squared residuals of the general model is calculated. Then the restricted (specific) model is estimated and the sum of the squared residuals of this model is calculated. The third step is to test the restrictions imposed by comparing the sums of squared residuals of the ADLM and the restricted model using the $F$-statistic. Since the restricted model is simple in structure and has more degrees of freedom than the general ADLM when it is estimated, the specific model is preferred to the complicated ADLM if the restrictions are accepted.

\subsection{Diagnostic Tests}

There are a number of diagnostic tests/checks which must be implemented in order to evaluate the estimated model and to identify the most 'satisfactory' or 'acceptable' estimation. If any of the assumptions are violated, problems can arise with regard to the validity and reliability of the estimated parameters and models. In order to assess whether the coefficients estimated are theoretically meaningful, they must first be examined in terms of both sign and magnitude. Economic theory imposes certain constraints on the signs of coefficients; parameters with 'incorrect' signs are rejected on thegrounds of being theoretically implausible. A priori expectations exist with regard to the signs of coefficients. In general, an unexpected parameter sign or size arises as a result of deficiencies in the model itself (Walsh, 1997).For example, the presence of multicollinearity; the omission of a relevant variable; the inclusion of an unimportant variable.

Various statistical tests will be carried out so as to verify the acceptability, reliability, and robustness of the estimated regression result. For example, the Student $t$-Test will be used to test the statistical significance of the 
individual parameter estimates in the regression models. Concerning, the standard error of the coefficients. The standard error test will give a general guide to the likely accuracy of a regression parameter. The F-Test will be used to test for the overall significance of the model. It tests the simultaneous null hypothesis of all the parameter to be equal to zero in the regression model. The $\mathrm{R}^{2}$-Coefficient of Determination will beused to measure the goodness of fit of a regression line. It measures the proportion of the total variation in the dependent variable explain by the repressors in the model. The R-squared $\left(\mathrm{R}^{2}\right)$ value ranging from ' 0 ' to ' 1 ' or the 'corrected $\mathrm{R}$-squared' $\left(\mathrm{R}^{2}\right)$ which is adjusted for degrees of freedom indicates the explanatory power (goodness of fit) of the model.

Similarly, various econometric tests will be carried out in order to verify whether the estimated regression results conform to the classical (normal) linear regression model assumption. For example, the test of normality will be used to verify whether the error term is normally distributed. Precisely, the Jacque-Beva (JB) test will be used to verify this assumption. In the same vein, the test of heteroscedasticity will be used to verify the assumption of equal spread of the error variance (homoscedastic) between members of the same series of observations. The white's heteroscedasticity test (with no cross term) will be employed in the test. In addition, the test of autocorrelation will beused to verify the randomness of the error term between members of the same series of observations. As a result of the numerous assumptions and problems associated with the conventional Durbin-Watson (DW) test, the Breusch-Godfrey (LM) test will be employed to verify this hypothesis. To a follow up, the test of specification error will be used to verify whether the econometric regression model being estimated is correctly specified. The Ramsey's RESET (Regression Specification Error Test) will be employed. To verify the reliability of the estimated regression model in forecasting future values, the Henry Theil's inequality coefficient will be used.

The econometric software packages used for the analysis of this work are the Eviews 4.1 and SPSS 19 versions while the Microsoft Excel 2010 is used to enter the data.

5. Presentation and Analysis of Empirical Results

5.1 Descriptive Statistics and Correlation Results

Table $6 \mathrm{a}$ and $6 \mathrm{~b}$ (see Appendix) present the descriptive statistics and correlations matrix respectively for all the variables (dependent and independent variables). Generally, the result shows a low correlation between the variables, with the exception of POE and $\mathrm{CO} 2, \mathrm{POE}$ and URB, and POE and GDPC. Some of the explanatory variables are positively correlated with natural disaster (TEM, CO2, WIS, URB and POE) while some are negatively correlated (RAF, GDPC and PRG). The expectation is that RAF and PRG should be positively correlated with natural disaster (NAD) instead they showed negative correlation even though the degree of negative correlation is low. However, the simple correlation coefficient between the variables and natural disaster (NAD) show insignificance at the 0.01 and 0.05 levels in the 2-tailed test.

5.2 Unit Root Test Results

Using the Augmented Dickey-Fuller (ADF) test, the stationarity of the individual variables was tested. The null hypotheses of a random walk $(\mathrm{H} 0: \mu=0)$ against the alternate hypothesis of a stationary process $(\mathrm{H} 1: \mu<0)$ is tested by using Dickey and Fuller critical values. As depicted in Table 6a, the results of the stationarity test indicate that carbon dioxide (CO2) emissions, population growth rate (PRG) and Political/institutional vulnerability (POE) are non stationary at level in any of the conventional levels. On the other hand, at levels with intercept, economic development (GDPC) showed stationarityat 1\% significant level but became insignificant with linear trend. Rapid urban growth (URB) failed to show stationarity with intercept but was stationary with linear trend in level at $10 \%$ significant level. So also is natural disaster occurrence (NAD) significant at $1 \%$ level with linear trend. However, average temperature (TEM), rainfall (RAF)and wind speed(WIS) are stationary at level whether with intercept or linear trend.In order words, they were found to reject the null hypothesis "no stationary" at level. This indicates that these time series data are non-mean reverting, convergence toward their long-run equilibrium and variances are constant overtime. Since some variable are non stationary in level, the next task is to check if the variables are stationary in difference. This is in line with Granger (1969), Granger and Newbold (1974). As such, the same Augmented Dickey-Fuller (ADF) test is applied.

Table 6a: Augmented Dickey-Fuller (ADF) Unit Root Test in Level

\begin{tabular}{llll}
\hline Variables & Intercept & Linear Trend & $\begin{array}{l}\text { Order } \\
\text { Integration }\end{array}$ \\
\hline TEM & $-4.296893 *(9)[-3.596616]$ & $-5.112504 *(9)[-4.192337]$ & $1(0)$ \\
\hline RAF & $-6.091051 *(9)[-3.596616]$ & $-6.073567 *(9)[-4.192337$ & $1(0)$ \\
\hline CO2 & $-1.987759(9)[-3.596616]$ & $-2.115374(9)[-4.192337]$ & - \\
\hline
\end{tabular}




\begin{tabular}{llll}
\hline WIS & $-5.294050 *(9)[-3.600987]$ & $-5.343122^{*}(9)[-4.198503]$ & $1(0)$ \\
\hline GDPC & $-3.655511 *(9)[-3.621023]$ & $-1.587990(9)[-4.234972]$ & $1(0)$ \\
\hline URB & $-1.419016(9)[-3.596616]$ & $-3.199481 * * *(9)[-3.191277]$ & $1(0)$ \\
\hline PRG & $-1.672438(9)[-3.596616]$ & $-2.229717(9)[-4.192337]$ & - \\
\hline POE & $-2.282445(9)[-3.596616]$ & $-3.075318(9)[-4.192337]$ & - \\
\hline NAD & $-2.008288(9)[-3.605593]$ & $-8.208143 *(9)[-4.192337]$ & $1(0)$ \\
\hline
\end{tabular}

Note: * significant at 1\%; ** significant at 5\%, *** significant at 10\% .ADF critical values are shown in parenthesis. The lag lengths shown in brackets are selected using the minimum Schwarz and Akaike Information criteria.

Source: Stationarity test results from analysis using Eviews 4.0

As can be seen in Table 6b, for all the variables, the Augmented Dickey-Fuller test statistics were less than the critical values at $1 \%, 5 \%$ and $10 \%$ levels of significance. The results of the stationarity test indicate that carbon dioxide $(\mathrm{CO} 2)$ emissions, population growth rate (PRG) and Political/institutional vulnerability (POE) are now stationary at first difference. That is, they are integrated of order one I (1). This means that in the short run, the variables are stable. To verify the result of the above test, the DF-GLS test is thereby applied.

Table 6b: Augmented Dickey-Fuller Unit Root Test in Difference

\begin{tabular}{llll}
\hline Variables & Intercept & Linear Trend & $\begin{array}{l}\text { Order } \\
\text { Integration }\end{array}$ \\
\hline TEM & $-10.78070 *(9)[-3.600987]$ & $-10.64100 *(9)[-4.198503]$ & $1(1)$ \\
\hline RAF & $-10.09870 *(9)[-3.600987]$ & $-9.981021 *(9)[-4.198503]$ & $1(1)$ \\
& & & \\
\hline CO2 & $-6.635362 *(9)[-3.600987]$ & $-6.568786 *(9)[-4.198503]$ & $1(1)$ \\
\hline WIS & $-5.992423 *(9)[-3.610453]$ & $-5.918662 *(9)[-4.211868]$ & $1(1)$ \\
\hline GDPC & $-3.542123^{* *}(9)[-2.945842]$ & $-3.390824 * * *(9)[-3.202445]$ & $1(1)$ \\
& & & \\
\hline URB & $-7.181967 *(9)[-3.600987]$ & $-7.225526 *(9)[-4.198503]$ & $1(1)$ \\
\hline PRG & $-4.915900 *(9)[-3.600987]$ & $-4.671687 *(9)[-4.198503]$ & $1(1)$ \\
\hline POE & $-7.695598^{*}(9)[-3.600987]$ & $-7.597783 *(9)[-4.198503]$ & $1(1)$ \\
\hline NAD & $-8.491946 *(9)[-3.605593]$ & $-8.430518 *(9)[-4.205004]$ & $1(1)$ \\
\hline
\end{tabular}

Note: * significant at 1\%; ** significant at $5 \%, * * *$ significant at $10 \%$. ADF critical values are shown in parenthesis. The lag lengths shown in brackets are selected using the minimum Schwarz and Akaike Information criteria.

Source: Stationarity test results from analysis using Eviews 4.0

Table $6 \mathrm{c}$ shows that most of the variables were stationary at level, since each reported t-statistic is not smaller than the critical test values. However, the results of the tests shows the presence of unit roots in urbanization rate (URB) 
and population growth rate (PRG) variables. First difference operation is all that is required to bring these variables to stationarity as depicted in Table $6 \mathrm{c}$ below.

Table 6c: DF-GLS test Result on Variables

\begin{tabular}{lllll}
\hline Variables & At level & $\begin{array}{l}\text { Order of } \\
\text { integration }\end{array}$ & First difference & Order of Integration \\
\hline TEM & -4.189232 & $1(0)$ & -10.63576 & $1(1)$ \\
\hline RAF & -6.163155 & $1(0)$ & -10.21979 & $1(1)$ \\
\hline CO2 & -1.654473 & $1(0)$ & -6.637115 & $1(1)$ \\
\hline WIS & -5.043018 & $1(0)$ & -7.070265 & $1(1)$ \\
\hline GDPC & -2.410385 & $1(0)$ & -6.098260 & $1(1)$ \\
\hline URB & 0.121186 & - & -7.029838 & $1(1)$ \\
\hline PRG & -1.636577 & - & -3.443879 & $1(1)$ \\
\hline POE & -2.096869 & $1(0)$ & -7.783140 & $1(1)$ \\
\hline NAD & -8.324248 & $1(0)$ & -8.611630 & $1(1)$ \\
\hline
\end{tabular}

Note: $1 \%, 5 \%$ and 10\%DF-GLS critical test values at level are-2.621185, -1.948886 and -1.611932 respectively. While 1\%, 5\% and 10\% DF-GLS critical test values at first difference are -2.622585,-1.949097 and -1.611824 respectively.

Source: Stationarity test results from analysis using Eviews 4.0

\subsection{Result of Co-Integration Test}

Since some of the variables are integrated at an order 1(0) and of the order 1(1). There is need to test for possible cointegration among these variables. The Engle and Granger two-step method is adopted. The long run relations among the variables is estimated by OLS and stationarity of the residuals is tested. Again, ADF and DF tests were employed to test for cointegrated variables. The results of cointegrationtests are reported in Table $7 \mathrm{a}$ and $7 \mathrm{~b}$.

Table 7a: ADF test Result on Residual

\begin{tabular}{|c|c|c|c|c|c|}
\hline \multirow{2}{*}{$\begin{array}{l}\text { Variable } \\
\text { Residual }\left(\mu_{\mathrm{t}}\right)\end{array}$} & \multicolumn{3}{|l|}{ ADF statistic Level } & \multicolumn{2}{|c|}{ Critical values } \\
\hline & $\begin{array}{l}\text { Intercept Lag Order of Ir } \\
-9.366773\end{array}$ & $\begin{array}{l}\text { ration } \\
1(0)\end{array}$ & $\begin{array}{l}1 \% \\
-3.600987\end{array}$ & $\begin{array}{l}5 \% \\
-2.935001\end{array}$ & $\begin{array}{l}10 \% \\
-2.605836\end{array}$ \\
\hline & $\begin{array}{l}\text { Linear trend Lag Order c } \\
-9.293054\end{array}$ & $\begin{array}{l}\text { ategration } \\
1(0)\end{array}$ & $\begin{array}{l}1 \% \\
-4.198503\end{array}$ & $\begin{array}{l}5 \% \\
-3.523623\end{array}$ & $\begin{array}{l}10 \% \\
-3.192902\end{array}$ \\
\hline & $\begin{array}{ll}\text { None } & \text { Lag } \\
\text { Integration } & \\
-9.486447 & \text { (9) }\end{array}$ & Order of & $\begin{array}{l}1 \% \\
-2.622585\end{array}$ & $\begin{array}{l}5 \% \\
-1.949097\end{array}$ & $\begin{array}{l}10 \% \\
-1.611824\end{array}$ \\
\hline
\end{tabular}

Source: Stationarity test results from analysis using Eviews 4.0 
Table 7b: DF-GLS test Result on Residual

\begin{tabular}{|c|c|c|c|c|}
\hline \multirow{3}{*}{$\begin{array}{l}\text { Variable } \\
\text { Residual }\left(\mu_{t}\right)\end{array}$} & \multicolumn{2}{|l|}{ DF-GLS statistic Level } & \multicolumn{2}{|c|}{ Critical values } \\
\hline & Intercept Lag Order of Integration & $\underline{1 \%}$ & $5 \%$ & $10 \%$ \\
\hline & $\begin{array}{lll}-2.387739 & (9) & 1(0)\end{array}$ & -2.625606 & -1.949609 & -1.611593 \\
\hline & Linear trend Lag Order of Integration & $\underline{1 \%}$ & $5 \%$ & $10 \%$ \\
\hline & $\begin{array}{lll}-8.383332 & (9) & 1(0)\end{array}$ & -3.770000 & -3.190000 & -2.890000 \\
\hline
\end{tabular}

Source: Stationarity test results from analysis using Eviews 4.0

Given the ADF and DF 1\%, 5\% and 10\% critical t-values, variables in the multivariate regression of equation 4 are said to be cointegrated. Therefore, $\mathrm{H}_{\mathrm{o}}$ is rejected, i.e., there is a long run relationship among the variables of the model at the chosen critical level. The solved static long run equation is reported in Tables $8 \mathrm{a}$ and $8 \mathrm{~b}(\mathrm{see}$ Appendix).The results from the estimated static model shows that DLOG(TEM), LOG(GDPC) and LOG(URB) are long-run determinants of natural disasters in Nigeria.

The regression results show that DLOG(TEM) has significant impact on the occurrence of natural disaster in Nigeria. It is estimated from the result that $1 \%$ increase in DLOG(TEM)will, on the average lead to decrease by $6.4 \%$ in the occurrence of natural disaster. The sign borne by the parameter estimates is not in conformity with the economic a priori expectation. Changes in climate not only affect average temperatures in Nigeria, but also extreme temperatures, increasing the likelihood of weather-related natural disasters. However, effort is been made at reducing the emission of greenhouse gases which increase overall temperatures.

However, the sign borne by the parameter estimate of LOG(GDPC) does conform to the a priori expectation. The result shows a negative relationship between LOG(GDPC) and NAD. That is, a $1 \%$ increase in LOG(GDPC) decreases the occurrence of natural disaster by $0.41 \%$. This implies that economic development plays an important part in reducing the occurrence of natural disasters in Nigeria. Although Nigerian economy has been growing, the economic growth is not accompanied by a structural change of the Nigerian economy. The economy lacks diversification and agricultural production lacks modernisation. To address this, the government is encouraging the diversification of the Nigerian economy away from the oil and gas sector. It is addressing the infrastructure deficit in the country and the development of the agricultural sector through modernisation and the establishment of staplecrop processing zones, with the value chain model to provide linkages to the manufacturing sector.

The coefficient of LOG(URB) is about 2.25 , meaning that holding other variables constant, 1percent increase in the $\log$ of urbanization rate (URB) leads to an increase in the occurrence of natural disaster by about 2.25 percent. In Nigeria urban growth is informed by natural population increases in the urban areas, rural - urban migration, creation of administrative towns and population concentration in towns blessed with natural resources. This high concentration of people beyond the facilities necessary to sustain the growth creates unhealthy competition for the available facilities and opportunities, especially housing. Poorly planned and managed houses increasingly occur in peripheral zones of marginal habitation, leaving hundreds of millions of people at the mercy of natural disasters. Vulnerability is acute along coastal areas where any land remaining available for urban growth is generally riskprone. Thus the rapid rate of urbanization in Nigeria is characteristic of economic growth without development. The variable TEM is important but it does not significantly affect the occurrence of natural disaster positively. Also, the variable RAF (rainfall) is necessary in the model but appear insignificant at any conventional levels. Nigeria has a rainy season and suffers from seasonal flash floods. These flash foods are sometimes lethal, especially in the rural areas or overcrowded slums, where drainage is poor or does not exist at all. Suffice to say that the ravaging global warming has massively contributed to the intensity of rainfall and the consequent flooding in parts of Nigeria. Nigeria suffered its worst floods in 40 years in 2012. Hundreds of people were killed and millions more were displaced (Murdock, 2012).

Table 8a (see Appendix) shows that the variance inflation factors (VIF's) for the explanatory variables in the regression model are less suggesting the absence of multicollinearity. This is also confirmed by the Durbin-Watson statistics of 2.654 implying absence of serial correlation (Table 8b see Appendix).

The next move was to switch to a short run model with an error correction mechanism as shown in equation 6 . The estimated form of equation 6 is shown in Table 9 (see Appendix). In the over-parameterized error correction model in Table 9, all the variables were lagged. Later, it was reduced to a parsimonious model through the elimination of insignificant variables. This led to the final estimation in Table 10 which is then used for further analysis. Moreover, the parsimonious model is preferred since it has lower Schwartz Criterion (SC) and standard deviation. 
Table 10 shows that the model gives a reasonable good fit. This is so because the explanatory variables accounted for 56 percent of the total variation in natural disasters (NAD). The remaining 44 percent are due to factors exogenous to the model but being taken care of by the error term. The F-ratio of 4.92 confirms the overall significance of the explanatory variables taken together while the Durbin-Watson statistics of 1.98 only corroborates findings that the residual of the model contains insignificant serial correlation, i.e., it suggests lesser degree of autocorrelation. The coefficient of the error correction term is statistically significant and carries the expected negative sign at both 5\% and $1 \%$ level of significant. It shows 44.3 percent speed of adjustment of disequilibrium in natural disaster (NAD) in the previous year which is corrected in the current year.

The results of the short run error correction model in Table 10 reveal that the coefficients of DLOG(CO2), DLOG(WIS), LOG(GDPC), LOG(URB), DLOG(GDPC(-2)) and LOG(URB(-1))seem to be significant and helpful in explaining the occurrence of natural disaster (NAD)in Nigeria. Still from Table 10, a unit change in DLOG(CO2) brings about 0.8 increase in the occurrence of natural disaster thereby suggesting that there are other relevant variables apart from DLOG(CO2) that can lead to natural disaster (NAD). In Nigeria, carbon dioxide emissions from fossil fuels have increased significantly over the last century. The transport sector accounts for a major share of fossil fuel consumption, hence it is very likely that the sector has a strong influence in this upward trend. The release of greenhouse gases (GHGs) into the atmosphere each year-mostly in the form of carbon dioxide $\left(\mathrm{CO}_{2}\right)$ contributing to climate change which in turn leads to the occurrence of natural disasters.

LOG(URB(-1)) shows that given other variables, 1percent increase in previous URB leads to about 7.51 percent decrease in current NAD. This is significant at 5 percent level of significance. Also, a unit change in the second period lag of the first difference of $\log$ GDPC leads to about 0.49 percent decrease in current NAD. It was also discovered that a unit increase in DLOG(WIS), other things being equal, will increase the occurrence of natural disaster (NAD) by 1.23 and vice-versa. Similarly, a unit increase in LOG(URB) will increase NAD by 10.60 and vice-versa. The magnitude of the increase is higher than it was in the long run static estimate. Finally, a unit increase in the value of LOG(GDPC), other variables held constant, will lead to 0.23 decrease in the occurrence of natural disaster (NAD). The size of the coefficient is less than it was in the long run estimates. The LOG(WIS) was shown to have a negative sign contrary to apriori expectation and it showed statistically insignificant coefficient but because of its importance a redundant variables test was carried out to know whether it should have been dropped from the parsimonious model. Despite its wrong sign and statistical insignificant coefficient, the result in Table 11(see Appendix) shows that the variable should not be deleted from the short run error correction model

The diagnostic tests results in Table $12-15$ (see Appendix) show that the model for the occurrence of natural disaster (NAD) qualifies all the diagnostic tests. The model is free from the problems of serial correlation, heteroscedasticity and that the error terms are normally distributed as shown by the Jacque - Bera (JB) test of normality in Figure 1(see Appendix). The Ramsey Regression specification Error Test (RESET) with F-distribution of 0.281444 concludes that the estimated model is correctly specified; that is, there is no specification error.

Stability of the model is checked through the graphs of CUSUM and CUSUM Squares tests in Figures 2 and 3 (see Appendix). The CUSUM and CUSUM Squares tests confirm that the model is stable as the calculated line lies inside the critical bounds at 5 percent level of significance. If the lines cross the critical bounds then the proposed model is unstable. The results in figures 2 and 3 show that the lines are within the critical bounds, so model is statistically stable.

Both graphical and forecast evaluation output for the dependent variable NAD is given in Figure 4 (see Appendix). The actual values of NAD are within the forecast interval for most of the forecast period. To test whether the value of the dependent variable at $t$ time might have come from the model fitted to all the data up to that point, a plot of the recursive residuals and standard errors was done using the One-Step Forecast test. The plot helps to spot the periods when the equation is least successful. For the test equation, there is evidence of instability early in the sample period especially around 1990 (see Figure 5 in Appendix).

6. Summary of Findings, Conclusion and Policy Implications

The empirical model is developed in the light of recent developments in the methodology of econometric modeling and the analysis of time series with stochastic non-stationary components. In modeling the natural disaster equation, the paper examined each series from 1970 -2015enteringthe model to ensure the stationary and the order of integration. The results of the Augmented Dickey-Fuller(ADF) unit root test show that most of the variables were stationary at level while the other variables were stationary at first difference(integrated of order one). Using the residual-based test for cointegration within an autoregressive distributed lag (ARDL) framework and error correction specification. The findings indicated that all the variables had significant existence in co integrated vector. This means that all the variables had long term equilibrium existence. The results from the estimated static long run model shows that DLOG(TEM), LOG(GDPC) and LOG(URB) are determinants of natural disasters in Nigeria. The short run error correction model results revealed that the coefficients of DLOG(CO2), DLOG(WIS), 
LOG(GDPC), LOG(URB), DLOG(GDPC(-2)) and LOG(URB(-1)) have significant impact on the occurrence of natural disaster (NAD) in Nigeria.

The error correction term (ECM) is of the expected negative sign and also significant. The result shows that the occurrence of natural disaster in Nigeria has an automatic mechanism and that natural disaster in Nigeria responds to deviation from equilibrium in a balancing manner. The absolute value of the coefficient of the error-correction term indicates that about 44.3 per cent of the disequilibrium in the occurrence of natural disasters is offset by short-run adjustment in each year. In order words, a value of -0.443047 for the ECM coefficient suggests a fast speed of adjustment strategy of 44.3 per cent.

In conclusion, even if it is not possible to prevent natural disasters, much can be done to build capacities to reduce the vulnerabilities that too often lead to a crisis situation. Therefore, Nigerian government must embark on reducing urbanization growth by making sure that industries which forge linkages with rural occupations should be promoted to mitigate a high rural-urban migration. In that light, the sitting of new industries and the location of infrastructure should not be very close to the sea in order for them to be free from sea level rise.

The appropriate authority should prepare comprehensive hazard maps and vulnerability analysis for the country by compiling historical data of disaster occurrence; analyzing of meteorological, seismological and environmental records; and employing satellite imagery and the GIS system to plot the hazard maps. In addition, establishing of very effective early warning systems for meteorological, geophysical, biological, social and industrial hazards is required.

To achieve effective management of floods, compliance with planning and urban laws should be enforced; embankments and levies along rivers and coastline prone to flood should be build; establishing of rainstorm early warning system; establishing and monitor weather stations, river and tidal gauges; ensuring appropriate management of dams; ensuring proper maintenance of existing urban drainage channels; enforcing environmental sanitation laws in towns and cities.

Nigeria should focus more on economic activities that are tertiary in nature which generate little greenhouse gases. In that light, effort should be made to develop a technology that can capture at least $80 \%$ of carbon emitted by industries which are discharged into the atmosphere. Better still, a cleaner source of energy should be developed, instead of over dependence on fossil fuel energy that generates greenhouse gases.

To control the velocity and direction of wind speed, tree planting should be encouraged in Nigeria. This is can be done by encouraging viable forestation and reforestation programmes using tested drought resistant and economic tree species. In the same vein, the development and adoption of efficient wood stoves and alternative sources of fuel wood should be encouraged.

More effort should be made at translating Nigeria's economic growth into job creation and poverty alleviation. Emphasis should be on improving the quality of public investment projects; enhancing budgeting, public financial management and procurement processes; prudent debt management practices and an enhanced domestic revenue base.

References

ADRC (2003).Natural disaster and sustainable development. Natural disasters data book.http://desastres.usac.edu.gt/documentos/pdf/eng/doc16396/doc16396-2a.pdf.

Albala-Bertrand, J.M.(1993). Political economy of large natural disasters with special reference to developing countries. Oxford: Clarendon Press.

Articles (2013).Monetary Policy in Nigeria - The impact of monetary policy on Nigeria's economic growth.http://articlesng.com/monetary-policy-nigeria-impact-monetary-policy-nigerias-economic-g...

BBC (31 Aug. 2011). Nigeria floods: Death toll in Ibadan rises. http://www.bbc.co.uk/news/world-africa-14735726

BBC (24 Sept. 2010). Northern Nigeria flooding 'displaces two million'. http://www.bbc.co.uk/news/world-africa11409167

Benson, C., and Clay, E. J. (1998).The impact of drought on Sub-Saharan African economies: A preliminary examination. World Bank Technical Paper 401. Washington, D.C.

Chinedu, U. O. (2008).Internal displacement in Nigeria.Forced Migration Review, no. 31, 37. http://www.fmreview.org/FMRpdfs/FMR31/37.pdf.

DHA (1994). Disaster management trainingprogramme: Disasters and development. Geneva: UNDP/DHA.

ECLAC (2003). Handbook for estimating the socio-economic and environmental effects of natural disasters. Santiago, Chile: United Nations Economic Commission for Latin America and the Caribbean.

Ecological Problems (EP) (2011).Connection between climate change and CO2 emissions.http://ecologicalproblems.blogspot.com/2011/01/connection-between-climate-change-and.html

Girma, F.D. (2012). Relationship between inflation and economic growth in Ethiopia: An empirical analysis, 19802011.Thesis for the Master of Philosophy in Environmental and Development Economics Department of 
University

of

Oslo. https://www.duo.uio.no/bitstream/handle/10852/34012/MasterxThesis.pdf?sequence=1.

Granger, C (1969).Developments in the study of cointegrated economic variables.Oxford Bulletin of Economics and Statistics, 48 (3), 355-369.

Granger, C and Newbold P (1974).Spurious regressions in econometrics, Journal of Econometrica, 2, 111-120.

Gov.UK, (2013). Policy: Making sustainable development a part of all government policy and operations. https://www.gov.uk/government/policies/making-sustainable-development-a-part-of-all-governmentpolicy-and-operations

Guha-Sapir, D., Hargitt, D., and Hoyois, P. (2004). Thirty years of natural disasters 1974-2003: The numbers. Louvain: UCL PressesUniversitaires de Louvain.

Hess, P. (2013). Economic growth and sustainable development.Routledge.http://www.routledge.com/books/details/9780415679497/

IDMC (2012).Nigeria country profile.www.internal-displacement.org/africa/nigeria/2012/

IDMC (2012b).Nigeria: Displacement induced by natural disaster. http://www.internaldisplacement.org/idmc/website/countries.nsf/(httpEnvelopes)/1114C2F1CF5DD072C1257A07004E8B98? OpenDocument

ISDR (2003). Disaster reduction and sustainable development: Understanding the links between vulnerability and risk to disasters related to development and environment. World Summit on Sustainable Development.http://www.osn.cz/soubory/dr-and-sd-english.pdf

Koutsoyiannis, A. (2001). Theory of econometrics (New York: PALGRAVE - Houndmills, Basingstoke, Hampshire RG 21 6x 5 and 175 fifth Avenue).

Medecins San Frontieres (MSF) (2012). MSF responds to floods in Nigeria. http://www.doctorswithoutborders.org/news/article.cfm?id=6381

Mechler, R. (2003). Natural disaster risk management and financing disaster losses in developing countries. Karlsruhe: PhD Thesis, University Fridericiana Karlsruhe.

Munich, R.(2006). Topics geo.Annual review: Natural catastrophes 2005. Munich: Munich Re.

Murdock, H. ( 2012). Nigeria Braces for Flood Season.VOA.http://www.voanews.com/content/nigeria-braces-forflood-season/1682794.html

NA (n.d.).Nature's attack.http://naturesattack.jimdo.com/natural-disasters/

OCHA (15 Nov 2012). Floods Situation Report No. 2 (as of 15 November 2012). http://reliefweb.int/report/nigeria/floods-situation-report-no-2-15-november-2012

ODI (2005).Aftershocks: Natural disaster risk and economic development policy .Briefing Paper. http://www.odi.org.uk/sites/odi.org.uk/files/odi-assets/publications-opinion-files/2596.pdf

Odjugo, P.A.O. (2005). An analysis of rainfall pattern in Nigeria.Global Journal of Environmental Sciences, 4(2), 139-146.

Odjugo, P. A. O. (2012).Global natural disasters and their implications on human sustainability.Journal of Sustainable Development and Environmental Protection, 2 (1), 18-35.

Odjugo, P.A.O. (2012). Valuing the cost of environmental degradation in the face of changing climate: Emphasis on flood and erosion in Benin City, Nigeria.African Journal of Environmental Science and Technology, 6(1), $17-27$.

Orhewere, M. (2012).Nigeria's brand of disaster management.Daily Times. http://www.dailytimes.com.ng/opinion/nigeria\%E2\%80\%99s-brand-disaster-management.

Shuaib, Y. A. (2009). NEMA and the challenge of managing disaster in Nigeria

Sunday Tribune (15 May 2011). Nigerian Tribune. http://tribune.com.ng/news2013/index.php/en/

Tribune (2012).Managing natural disasters.http://tribune.com.ng/index.php/editorial/50464-managing-naturaldisasters.

UNDP (2013).The rise of the South: Human progress in a diverse world. Human Development Report 2013.http://hdrstats.undp.org/images/explanations/NGA.pdf.

U.S. DOS (U.S. Department of State) (2011). 2010 Country Reports on Human Rights Practices: Nigeria.

Vanguard (7 April 2012).Travails of the displaced.http://www.vanguardngr.com/2012/04/travails-of-the-displaced/

VRSD (n.d.).Vulnerability reduction for sustainable development.http://www.osn.cz/soubory/dr-and-sd-english.pdf.

Walsh, M. (1997).Demand analysis in Irish tourism. Journal of the Statistical and Social Inquiry Society of Ireland, Vol. XXVII, Part IV, Page1-35.

Wikipedia (2012).Economy of Nigeria. http://en.wikipedia.org/wiki/Economy_of_Nigeria

Zenklusen,O. (2007).Natural disasters and economic development: A neoclassicalreview oftheoretical perspectives and empirical evidence. D I S S E R T A T I O N of the University of St. Gallen, Graduate School of 
Business Administration, Economics, Law and Social Sciences (HSG). http://verdi.unisg.ch/www/edis.nsf/SysLkpByIdentifier/3321/\$FILE/dis3321.pdf.

Appendix

Table 5: Top 10 Natural Disasters in Nigeria for the period of 1980-2011 sorted by numbers of people affected, killed and economic damage cost

\begin{tabular}{|c|c|c|c|c|c|c|c|c|}
\hline \multicolumn{3}{|c|}{ Number of People Affected } & \multicolumn{3}{|c|}{ Number of People killed } & \multicolumn{3}{|c|}{ Economic Damage Cost } \\
\hline Disasters & Date & $\begin{array}{l}\text { Total No } \\
\text { Affected }\end{array}$ & $\begin{array}{l}\text { Disaster } \\
\mathbf{s}\end{array}$ & Date & $\begin{array}{l}\text { No } \\
\text { Killed }\end{array}$ & Disasters & Date & $\begin{array}{l}\text { Damage } \\
\text { (000 US\$ } \\
\text { ) }\end{array}$ \\
\hline Drought & Jun-83 & $\begin{array}{l}3,000,00 \\
0\end{array}$ & Epidemic & $\begin{array}{l}\text { 6-Мay- } \\
91\end{array}$ & 7,289 & Drought & Jun-83 & 71,103 \\
\hline Flood & $\begin{array}{l}13 \text {-Sep- } \\
10\end{array}$ & $\begin{array}{l}1,500,20 \\
0\end{array}$ & Epidemic & Feb-96 & 4,346 & Flood & $\begin{array}{l}11-\text { Sep- } \\
94\end{array}$ & 66,500 \\
\hline Flood & $\begin{array}{l}11-\text { Sep- } \\
94\end{array}$ & 580,000 & Epidemic & Oct-69 & 2,000 & Flood & $\begin{array}{l}13 \text {-Sep- } \\
10\end{array}$ & 30,000 \\
\hline Flood & Aug-88 & 300,000 & Epidemic & $\begin{array}{l}\text { 1-Jan- } \\
09\end{array}$ & 1,701 & Flood & $\begin{array}{l}\text { 23-Sep- } \\
85\end{array}$ & 8,000 \\
\hline Flood & 5-Sep-03 & 210,000 & Epidemic & $\begin{array}{l}19-\mathrm{Feb}- \\
96\end{array}$ & 1,193 & Flood & $\begin{array}{l}20-\text { Sep- } \\
00\end{array}$ & 4,805 \\
\hline Flood & $\begin{array}{l}10 \text {-Sep- } \\
09\end{array}$ & 150,000 & Epidemic & Nov-86 & 1,000 & Flood & $\begin{array}{l}27 \text {-Aug- } \\
01\end{array}$ & 3,000 \\
\hline Flood & $\begin{array}{l}10 \text {-Oct- } \\
98\end{array}$ & 100,000 & Epidemic & $\begin{array}{l}\text { 27-Jun- } \\
11\end{array}$ & 694 & Flood & 5-Sep-03 & 2,570 \\
\hline Flood & $\begin{array}{l}\text { 15-Sep- } \\
99\end{array}$ & 90,000 & Epidemic & $\begin{array}{l}28-F e b- \\
05\end{array}$ & 561 & Flood & $\begin{array}{l}15 \text {-Aug- } \\
00\end{array}$ & 1,900 \\
\hline Flood & $\begin{array}{l}\text { 27-Aug- } \\
01\end{array}$ & 84,065 & Epidemic & Apr-91 & 400 & Flood & $\begin{array}{l}28 \text {-Aug- } \\
11\end{array}$ & 1,500 \\
\hline Epidemic & Oct-69 & 80,000 & Epidemic & $\begin{array}{l}\text { 23-Jul- } \\
10\end{array}$ & 353 & Flood & $\begin{array}{l}\text { 7-Aug- } \\
05\end{array}$ & 147 \\
\hline Total & & $\begin{array}{l}6,094,26 \\
5\end{array}$ & Total & & 19,537 & Total & & 189.525 \\
\hline
\end{tabular}

Source: Odjugo (2012).

\begin{tabular}{|c|c|c|c|c|c|c|c|c|c|}
\hline & $\begin{array}{l}\text { LOG(T } \\
\text { EM) }\end{array}$ & $\begin{array}{l}\text { LOG(R } \\
\text { AF) }\end{array}$ & $\begin{array}{l}\text { LOG( } \\
\text { CO2) }\end{array}$ & $\begin{array}{l}\text { LOG(W } \\
\text { IS })\end{array}$ & $\begin{array}{l}\text { LOG(G } \\
\text { DPC) }\end{array}$ & $\begin{array}{l}\text { LOG(U } \\
\text { RB) }\end{array}$ & $\begin{array}{l}\text { LOG(P } \\
\text { RG) }\end{array}$ & POE & $\overline{\text { NAD }}$ \\
\hline Mean & 3.322620 & 5.289438 & $\begin{array}{c}11.0227 \\
1\end{array}$ & 1.382663 & 6.063567 & 1.185547 & 0.960060 & $\begin{array}{c}0.4418 \\
60\end{array}$ & 0.465116 \\
\hline Median & 3.317816 & 5.300315 & $\begin{array}{c}11.0913 \\
8\end{array}$ & 1.354546 & 5.909549 & 1.193922 & 0.996949 & $\begin{array}{c}0.0000 \\
00\end{array}$ & 0.000000 \\
\hline Maximum & 3.424263 & 5.587249 & $\begin{array}{c}11.5525 \\
7\end{array}$ & 1.621959 & 7.740664 & 1.335001 & 1.043804 & $\begin{array}{c}1.0000 \\
00\end{array}$ & 1.000000 \\
\hline Minimum & 3.295837 & 4.865995 & $\begin{array}{c}10.4607 \\
3\end{array}$ & 1.139434 & 5.115716 & 0.993252 & 0.662688 & $\begin{array}{c}0.0000 \\
00\end{array}$ & 0.000000 \\
\hline Std. Dev. & 0.021910 & 0.137207 & $\begin{array}{c}0.29312 \\
3\end{array}$ & 0.130730 & 0.612226 & 0.092049 & 0.105636 & $\begin{array}{c}0.5024 \\
86\end{array}$ & 0.504685 \\
\hline Skewness & 2.401359 & $\begin{array}{c}- \\
0.969375\end{array}$ & 0.03516 & 0.148466 & 1.159258 & 0.016772 & -1.608022 & 0.2341 & 0.139876 \\
\hline
\end{tabular}




\begin{tabular}{|c|c|c|c|c|c|c|c|c|c|}
\hline & & & 0 & & & & & 46 & \\
\hline Kurtosis & 11.74144 & 5.166725 & $\begin{array}{c}1.94432 \\
8\end{array}$ & 1.949658 & 4.215383 & 2.333972 & 4.744990 & $\begin{array}{c}1.0548 \\
25\end{array}$ & 1.019565 \\
\hline Jarque-Bera & 178.2331 & 15.14576 & $\begin{array}{c}2.00557 \\
2\end{array}$ & 2.134569 & 12.27771 & 0.796787 & 23.98671 & $\begin{array}{c}7.1720 \\
52\end{array}$ & 7.167353 \\
\hline Probability & 0.000000 & 0.000514 & $\begin{array}{c}0.36685 \\
6 \\
\end{array}$ & 0.343941 & 0.002157 & 0.671398 & 0.000006 & $\begin{array}{c}0.0277 \\
08\end{array}$ & 0.027773 \\
\hline Sum & 142.8727 & 227.4458 & $\begin{array}{c}473.976 \\
5 \\
\end{array}$ & 59.45452 & 260.7334 & 50.97852 & 41.28258 & $\begin{array}{c}19.000 \\
00 \\
\end{array}$ & 20.00000 \\
\hline $\begin{array}{l}\text { Sum Sq. } \\
\text { Dev. }\end{array}$ & 0.020161 & 0.790679 & $\begin{array}{c}3.60868 \\
0 \\
\end{array}$ & 0.717791 & 15.74245 & 0.355869 & 0.468679 & $\begin{array}{c}10.604 \\
65\end{array}$ & 10.69767 \\
\hline Observations & 43 & 43 & 43 & 43 & 43 & 43 & 43 & 43 & 43 \\
\hline
\end{tabular}

Table 6a: Descriptive Statistics

Source: Author's Estimation using Eviews 4.0.

Table 6b: Pearson Correlation Matrix

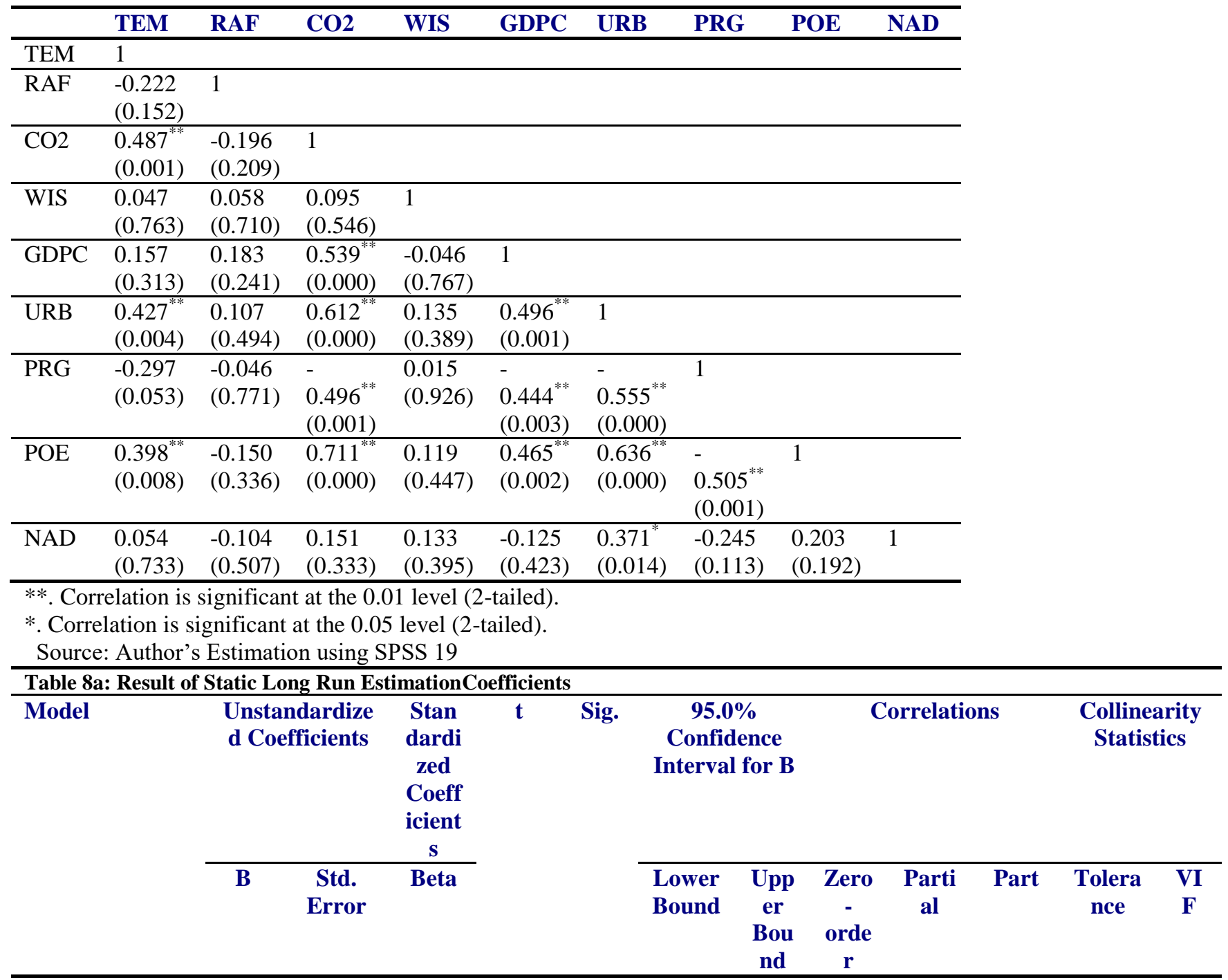




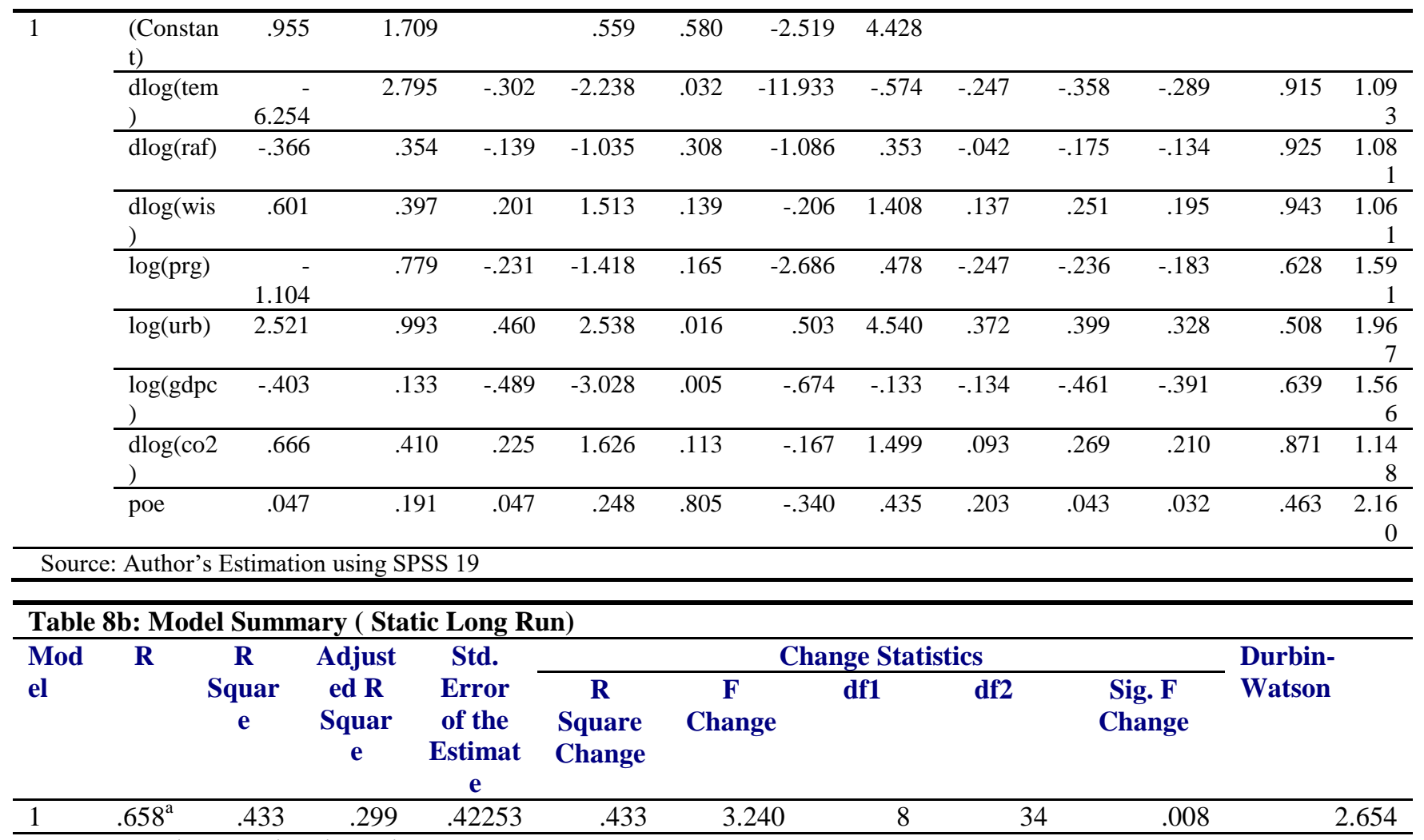

Source: Author's Estimation using SPSS 19

\begin{tabular}{ccccc}
\hline \multicolumn{2}{c}{ Table 9: Over-Parameterized Error Correction Model } \\
\hline Variable & $\begin{array}{c}\text { Coefficien } \\
\mathbf{t}\end{array}$ & Std. Error & t-Statistic & Prob. \\
\hline C & 14.54585 & 15.20703 & 0.956522 & 0.3492 \\
\hline LOG(TEM) & -3.160734 & 4.162950 & -0.759253 & 0.4558 \\
\hline LOG(RAF) & -0.363992 & 0.627564 & -0.580008 & 0.5678 \\
\hline DLOG(CO2) & 0.968087 & 0.478086 & 2.024925 & 0.0552 \\
\hline DLOG(WIS) & 1.311114 & 0.673748 & 1.946001 & 0.0645 \\
\hline LOG(GDPC) & -0.373245 & 0.275818 & -1.353230 & 0.1897 \\
\hline LOG(URB) & 7.363983 & 4.344310 & 1.695087 & 0.1042 \\
\hline DLOG(PRG) & 1.076444 & 1.594759 & 0.674989 & 0.5067 \\
\hline POE & -0.087065 & 0.262085 & -0.332199 & 0.7429 \\
\hline ECM(-1) & -0.403471 & 0.626984 & -0.643511 & 0.5265 \\
\hline DLOG(TEM(-1)) & 3.426916 & 6.194118 & 0.553253 & 0.5857 \\
\hline DLOG(RAF (-1)) & 0.375765 & 0.438020 & 0.857872 & 0.4002 \\
\hline DLOG(CO2(-1)) & 0.032105 & 0.574586 & 0.055874 & 0.9559 \\
\hline LOG(WIS) & -0.890754 & 0.943498 & -0.944096 & 0.3554 \\
\hline DLOG(GDPC(-1)) & 0.001699 & 0.295554 & 0.005749 & 0.9955 \\
\hline LOG(URB (-1)) & -4.866011 & 3.976078 & -1.223822 & 0.2340 \\
\hline LOG(PRG) & -1.241566 & 1.242472 & -0.999272 & 0.3285 \\
\hline POE (-1) & 0.177780 & 0.246100 & 0.722389 & 0.4777 \\
\hline NDIS(-1) & -0.004560 & 0.611617 & -0.007456 & 0.9941 \\
\hline${ }^{2}=0.60 ;$ F-statistic & $1.89 ;$ D W 121 & & &
\end{tabular}

$\mathrm{R}^{2}=0.60 ;$ F-statistic $=1.89 ; \mathrm{D} . \mathrm{W}=2.1$

Source: Author's Estimation using Eviews 4.0. 


\begin{tabular}{crrrr}
\hline \multicolumn{2}{l}{ Table 10: Parsimonious Model } & & & \\
\hline Variable & $\begin{array}{r}\text { Coefficien } \\
\text { t }\end{array}$ & Std. Error & t-Statistic & Prob. \\
\hline $\mathrm{C}$ & -0.316394 & 1.281522 & -0.246889 & 0.8066 \\
\hline DLOG(CO2) & 0.785255 & 0.376684 & 2.084651 & 0.0454 \\
\hline DLOG(WIS) & 1.233072 & 0.507744 & 2.428531 & 0.0212 \\
\hline LOG(GDPC) & -0.229464 & 0.119147 & -1.925898 & 0.0633 \\
\hline LOG(URB) & 10.59663 & 3.628343 & 2.920516 & 0.0065 \\
\hline ECM(-1) & -0.443047 & 0.160161 & -2.766265 & 0.0095 \\
\hline DLOG(GDPC(-2)) & -0.487135 & 0.190127 & -2.562154 & 0.0155 \\
\hline LOG(URB(-1)) & -7.507716 & 3.591246 & -2.090560 & 0.0449 \\
\hline LOG(WIS) & -1.114064 & 0.676738 & -1.646228 & 0.1098 \\
\hline
\end{tabular}

$\mathrm{R}^{2}=0.56 ;$ F-statistic $=4.92 ; \mathrm{D} . \mathrm{W}=1.98$

Source: Author's Estimation using Eviews 4.0.

\begin{tabular}{llll}
\hline \multicolumn{4}{l}{ Table 11: Redundant Variables: LOG(WINS) } \\
\hline F-statistic & 2.710066 & Probability & 0.109819 \\
\hline Log likelihood ratio & 3.352371 & Probability & 0.067108 \\
\hline \multicolumn{4}{l}{ Source: Author's Estimation using Eviews 4.0. } \\
\begin{tabular}{lll} 
\\
\hline
\end{tabular} \\
\hline \multicolumn{4}{l}{ Table 12: Breusch-Godfrey Serial Correlation LM Test } \\
\hline Obs*R-squared & 0.591069 & Probability & 0.560268 \\
\hline
\end{tabular}

Source: Author's Estimation using Eviews 4.0.

\begin{tabular}{lcll}
\hline \multicolumn{4}{l}{ Table 13: White Heteroskedasticity Test } \\
\hline F-statistic & 0.996940 & Probability & 0.491553 \\
\hline Obs*R-squared & 16.38060 & Probability & 0.426728 \\
\hline
\end{tabular}

Source: Author's Estimation using Eviews 4.0.

\begin{tabular}{llll}
\hline Table 14: ARCH Test & & & \\
\hline F-statistic & 0.504247 & Probability & 0.482092 \\
\hline Obs*R-squared & 0.524358 & Probability & 0.468989 \\
\hline
\end{tabular}

Source: Author's Estimation using Eviews 4.0.

\begin{tabular}{lccc}
\hline \multicolumn{2}{l}{ Table 15: Ramsey RESET Test } & & \\
\hline F-statistic & 0.281444 & Probability & 0.599662 \\
\hline Log likelihood ratio & 0.373510 & Probability & 0.541097 \\
\hline
\end{tabular}

Source: Author's Estimation using Eviews 4.0. 

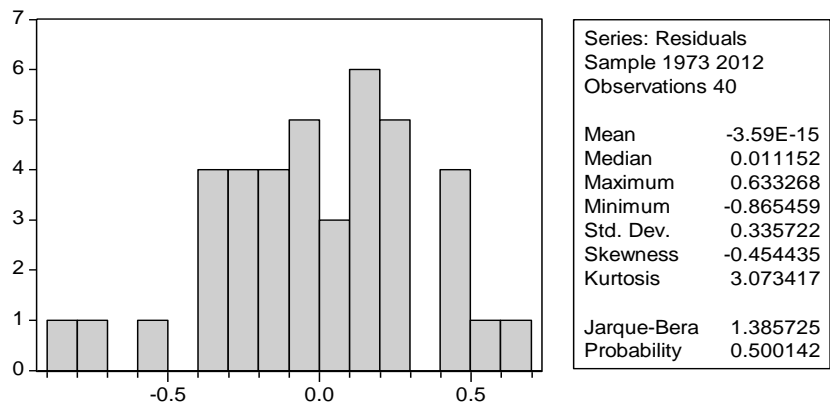

Figure 1: Normality Test Result

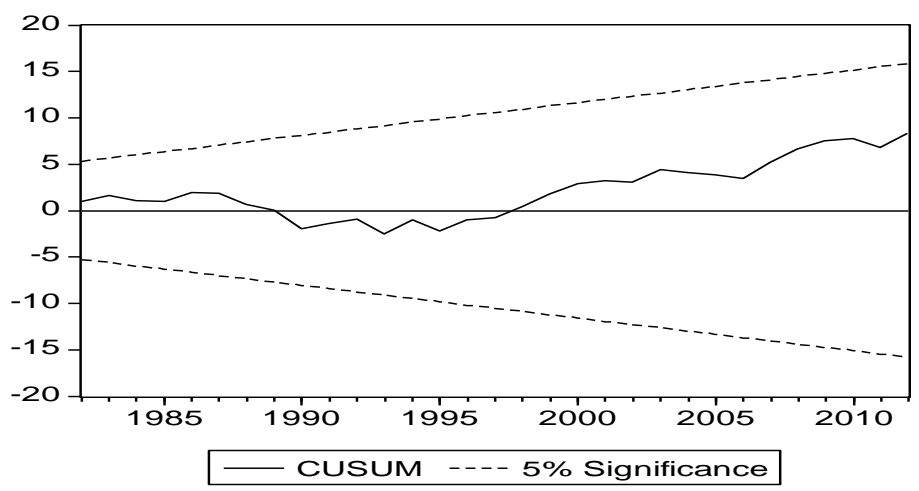

Figure 2: CUSUM Test Result

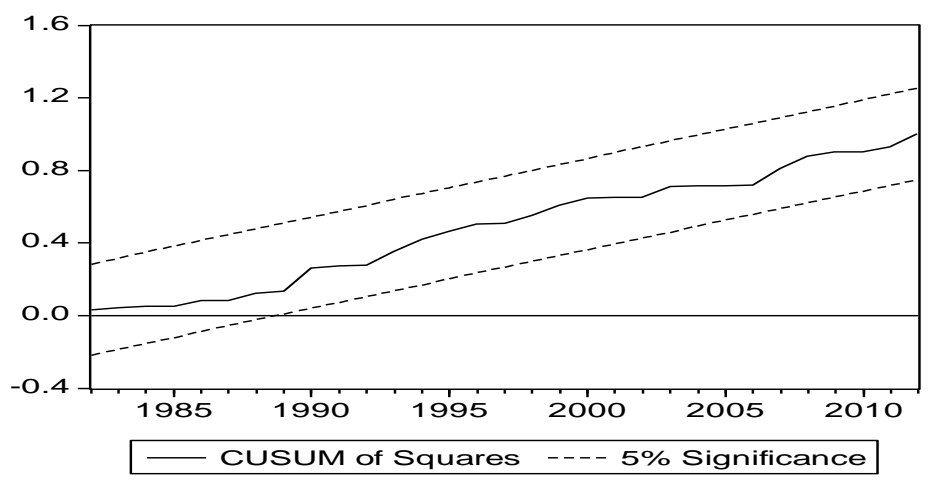

Figure 3: CUSUM of Squares Test Result

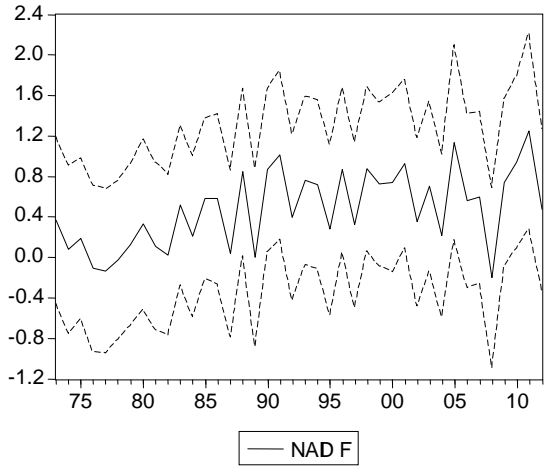

$$
\begin{array}{|ll|}
\hline \text { Forecast: NDISF } \\
\text { Actual: NDIS } \\
\text { Forecast sample: } 19702012 \\
\text { Adjusted sample: } 19732012 \\
\text { Included observations: } 40 \\
& \\
& \\
\text { Root Mean Squared Error } & 0.331499 \\
\text { Mean Absolute Error } & 0.263066 \\
\text { Mean Abs. Percent Error } & 12.98143 \\
\text { Theil Inequality Coefficient } & 0.256291 \\
\quad \text { Bias Proportion } & 0.000000 \\
\quad \text { Variance Proportion } & 0.144240 \\
\text { Covariance Proportion } & 0.855760 \\
\hline
\end{array}
$$

Figure 4: Forecast Evaluation Output for NAD Variable 


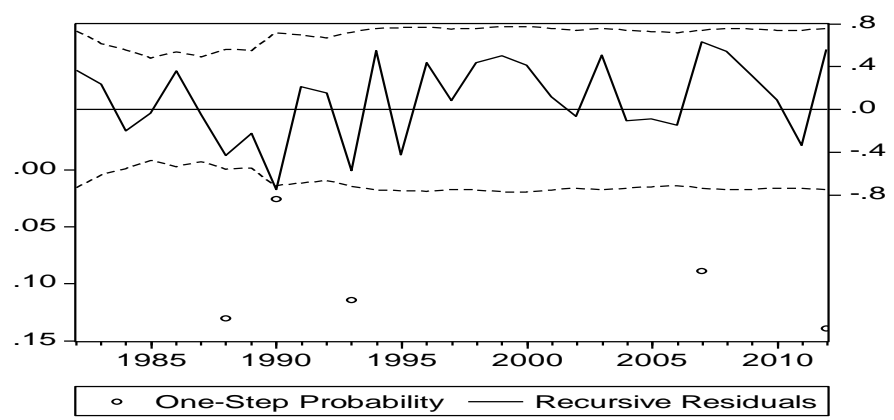

Figure 5: One-Step Forecast Test Result

Variables Excluded

There are other factors hypothesized to affect tourism demand levels but which have been omitted from estimation in this study. The inclusion or exclusion of certain other variables from the study means that the subsequent results are subject to biases entailed in mis-specification and omitted variables, particularly, if the variable excluded is correlated with the dependent variable. Essentially, it would prove impractical to attempt to include all possible variables in a regression model. Nonetheless, certain variables are excluded purely on grounds of inadequate data.

Indeed, loss of degrees of freedom means that only the most important variables remain. Some of the most obvious omissions in addition to reasons for their omission are as follows; access transport costs, marketing expenditure abroad and sociological factors.

\section{Copyrights}

Copyright for this article is retained by the author(s), with first publication rights granted to the journal.

This is an open-access article distributed under the terms and conditions of the Creative Commons Attribution license (http://creativecommons.org/licenses/by/4.0/) 